Article

\title{
Effect of Material and Process Variables on Characteristics of Nitridation-Induced Self-Formed Aluminum Matrix Composites-Part 2: Effect of Nitrogen Flow Rates and Processing Temperatures
}

\author{
Dae-Young Kim ${ }^{\circledR}$, Pil-Ryung Cha, Ho-Seok Nam, Hyun-Joo Choi * and Kon-Bae Lee * \\ School of Advanced Materials Engineering, Kookmin University, Seoul 02707, Korea; \\ kdy6603@kookmin.ac.kr (D.-Y.K.); cprdream@kookmin.ac.kr (P.-R.C.); hsnam@kookmin.ac.kr (H.-S.N.) \\ * Correspondence: hyunjoo@kookmin.ac.kr (H.-J.C.); kblee@kookmin.ac.kr (K.-B.L.); \\ Tel.: +82-2-910-4287 (H.-J.C.); +82-2-910-4230 (K.-B.L.)
}

Received: 8 January 2020; Accepted: 6 March 2020; Published: 8 March 2020

\begin{abstract}
The nitridation-induced self-formed aluminum matrix composite (NISFAC) process is based on the nitridation reaction, which can be significantly influenced by the characteristics of the starting materials (e.g., the chemical composition of the aluminum powder and the type, size, and volume fraction of the ceramic reinforcement) and the processing variables (e.g., process temperature and time, and flow rate of nitrogen gas). Since these variables do not independently affect the nitridation behavior, a systematic study is necessary to examine the combined effect of these variables upon nitridation. In this second part of our two-part report, we examine the effect of nitrogen flow rates and processing temperatures upon the degree of nitridation which, in turn, determines the amount of exothermic reaction and the amount of molten $\mathrm{Al}$ in the nitridation-induced self-formed aluminum matrix composite (NISFAC) process. When either the nitrogen flow rate or the set temperature was too low, high-quality composites were not obtained because the level of nitridation was insufficient to fill the powder voids with molten Al. Hence, since the filling of the voids in the powder bed by molten $\mathrm{Al}$ is essential to the NISFAC process, the conditions should be optimized by manipulating the nitrogen flow rate and processing temperature.
\end{abstract}

Keywords: aluminum matrix composites; aluminum nitride; nitridation; exothermic; NISFAC process

\section{Introduction}

We recently developed the nitridation-induced self-formed aluminum composite (NISFAC) process as a facile and innovative route to manufacturing $\mathrm{Al}$ matrix composites (AMCs) [1-3]. Whereas, previously, the limited wettability between the reinforcement and the $\mathrm{Al}$ matrix had to be overcome by the use of high-energy mechanical stirring (e.g., stir casting) [4-10], high-pressure infiltration of molten $\mathrm{Al}$ into a preform [11-16], or high-pressure consolidation of the powder mixture (powder metallurgy) [16-21], a key feature of the NISFAC process is its flexibility with respect to the selection of reinforcement regardless of the level of wettability [1-3]. Although the nitridation of aluminum has been investigated by a variety of in-situ techniques such as directed metal oxidation [22], pressureless metal infiltration [23], and reactive gas injection [24], etc., there have been limited studies on the nitridation-induced forming of aluminum matrix composites. In particular, we have examined the chemical and structural characteristics of the unique surface morphology of the AMCs produced from the initial powder state in the presence of nitrogen gas and have proposed an explanation for why the AMCs were produced only under a nitrogen atmosphere. In summary, both $\mathrm{Al}$ and $\mathrm{SiC}$ particles undergo surface modification during heating in a nitrogen atmosphere to improve wettability, 
resulting in AMCs. This suggests that the properties of the obtained AMCs can be freely tailored by manipulating the type, size, and volume fraction of the reinforcement to generate a number of combinations comparable with those available in alloy design. This also suggests that AMCs with identical properties can be produced with different combinations of $\mathrm{Al}$ matrix and reinforcement (or filler). As a result, the number of applicable AMCs can be greatly increased, thereby contributing to the expansion of end-user choice.

Although the nitridation-based NISFAC process is much simpler and easier than conventional processes, the degree of nitridation and, hence, the amount of molten $\mathrm{Al}$ generated during the process, is influenced by all relevant variables, including the composition of the $\mathrm{Al}$ matrix, the type, size, and volume fraction of reinforcement, and the fabrication temperature and time [1-3]. Therefore, it is essential to optimize the process conditions for the selected Al matrix and reinforcement (or filler) system. In the first part of our report, we examined the effects of the size and volume fraction of SiC particles, together with that of the process temperature, upon the Al 6061 alloy matrix composites containing SiC [3]. There we found that the most important factor for producing high-quality AMCs is the generation of sufficient molten $\mathrm{Al}$ to fill the voids in the powder bed. The amount of molten $\mathrm{Al}$ formed during heating in a nitrogen atmosphere is also determined by the temperature inside the powder bed, which is governed by the degree of nitridation and the process temperature. As mentioned earlier, nitridation is affected by almost all manufacturing parameters. Therefore, the effects of nitrogen flow rate and process temperature upon the production of AMCs consisting of the same $\mathrm{Al} 6061$ alloy matrix with an initial average $\mathrm{Al}$ powder size of $\sim 7 \mu \mathrm{m}$ and containing $\mathrm{SiC}$ with an initial average powder size of $\sim 40 \mu \mathrm{m}$ are examined in the present work.

\section{Materials and Methods}

The composites were produced in the same manner as in the first part of this study; $\mathrm{Al} 6061$ alloy was selected as the matrix and $\mathrm{SiC}$ particles were selected as the reinforcement. The average particle size of the Al 6061 alloy powder was $7.18 \mu \mathrm{m}$ (Chengdu Best New Materials Co., Ltd, Sichuan, China). The average size of the SiC particles was $40 \mu \mathrm{m}$ (Showa Denko, Toyama, Japan) and the volume fraction was fixed at 20\%. The $\mathrm{Al} 6061$ alloy powder and $\mathrm{SiC}$ particles were first mixed using a Turbula mixer (DM-T2, Daemyoung enterprise Co., LTD., Gwangmyeng, Korea). The mixture was then placed in a graphite crucible, charged in a furnace, heated in a nitrogen atmosphere at 610 to $650^{\circ} \mathrm{C}$ for $20-60 \mathrm{mins}$, then removed from the furnace and air cooled. The heating rate was $5^{\circ} \mathrm{C} / \mathrm{min}$, the nitrogen flow rate was 1-4 L/min, and the exhaust was conducted via a beaker filled with water to suppress the ingress of external oxygen. In addition, since the production of AMCs was significantly affected by the reaction between the $\mathrm{Al}$ powder and nitrogen gas (nitridation) during heating in a nitrogen atmosphere, the crucible weight was measured before and after heating in order to calculate degree of nitridation. The temperature change inside the powder bed due to the exothermic nitridation reaction was also measured with the aid of data acquisition software (Lutron, SW-U801-WIN) by inserting a thermocouple into the center of the powder bed. The phase-change behavior according to process temperature and nitrogen concentration was analyzed using an X-ray diffractometer (XRD, Rigaku D-max 2500, Tokyo, Japan). The microstructure of the prepared AMCs was observed using an optical microscope (Eclipse LV100ND, Nikon, Japan) and a scanning electron microscope (SEM, JSM 2001F, JEOL, Akishima, Japan) with energy-dispersive X-ray spectroscopy (EDS).

\section{Results and Discussion}

The key to determining the success of the NISFAC process is the formation of sufficient molten $\mathrm{Al}$ to fill the voids inside the powder bed. In particular, when the production temperature is lower than the melting point (or liquidus) of $\mathrm{Al}$ (or alloy), the $\mathrm{Al}$ powder can only melt when the temperature is locally increased due to the exothermic nitridation reaction. Hence, the amount of molten $\mathrm{Al}$ is determined by the degree of nitridation, which can be controlled by the various process parameters. 


\subsection{Effect of Nitrogen and Argon Gas}

Figure $1 \mathrm{a}$ shows the internal temperature of the powder bed when heating a mixture of $\mathrm{Al} 6061$ alloy and $\mathrm{SiC}\left(40 \mu \mathrm{m}, 20\right.$ vol.\%) from room temperature (RT) to $640{ }^{\circ} \mathrm{C}$ for $1 \mathrm{~h}$ under an atmosphere of argon or nitrogen $(2 \mathrm{~L} / \mathrm{min})$. For both types of atmosphere, the temperature of the powder bed increased at approximately the same rate during the heating from RT to $610{ }^{\circ} \mathrm{C}$. However, when the temperature of the powder bed exceeded $610^{\circ} \mathrm{C}$, a more rapid temperature increase was observed under the nitrogen atmosphere than the argon atmosphere. This is due to the exothermic nature of the nitridation reaction. Furthermore, under the nitrogen atmosphere, the temperature rise of the powder bed became rapid after reaching approximately $645^{\circ} \mathrm{C}$, and subsequently became more gradual as the temperature approached the maximum value of about $680{ }^{\circ} \mathrm{C}$.
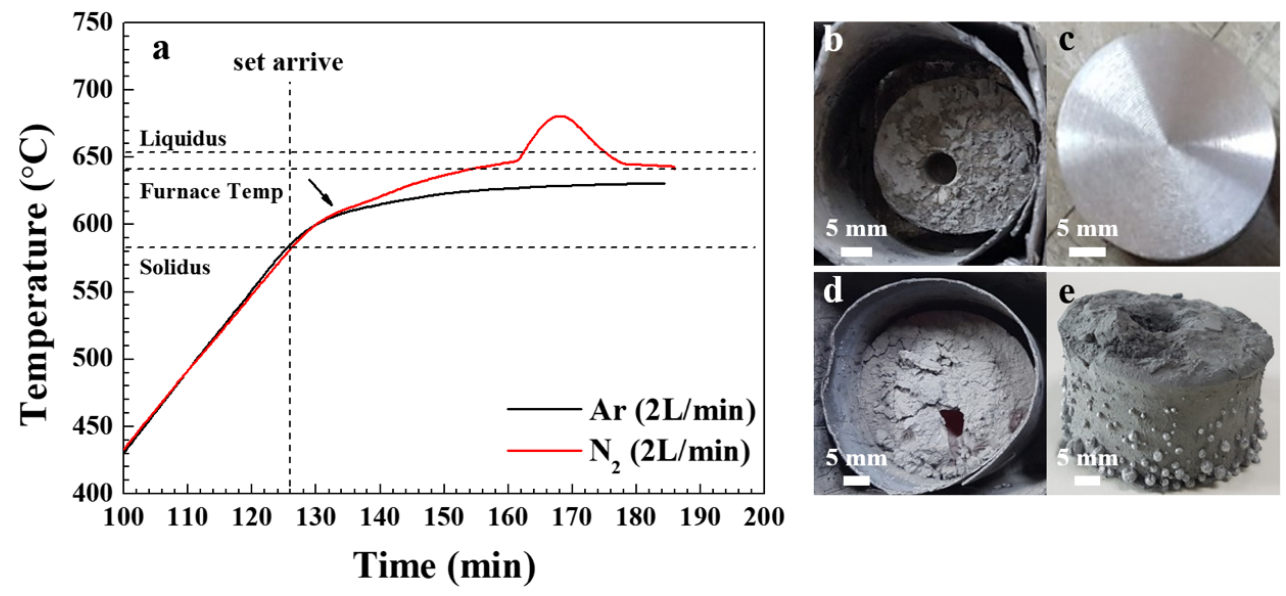

Figure 1. (a) The temperature variation of $20 \mathrm{vol} . \% \mathrm{SiC}(40 \mu \mathrm{m}) / \mathrm{Al} 6061$ composites during heating at a set temperature of $640{ }^{\circ} \mathrm{C}$ under nitrogen and argon atmospheres (flow rate: $2 \mathrm{~L} / \mathrm{min}$ ); (b-e) Photographic images of the composites produced under an atmosphere of nitrogen $(\mathbf{b}, \mathbf{c})$ and $\operatorname{argon}(\mathbf{d}, \mathbf{e})$ in the air-cooled crucibles (b,d) and after lathe working (c).

Photographic images of the air-cooled crucibles after heating for $1 \mathrm{~h}$ under a nitrogen or argon atmosphere, respectively, are presented in Figure $1 b, d$, while images of the respective samples after machine working are presented in Figure 1c. For the sample heated in nitrogen, the significant amount of shrinkage observed after cooling (Figure 1b) suggests that sufficient molten Al was produced during heating. Moreover, a bright metallic luster was obtained for this sample after lathe working (Figure 1c), demonstrating the production of a sound composite. When heated in argon, the maximum temperature inside the bed was $631^{\circ} \mathrm{C}$, which is lower than the programmed furnace target temperature of $640{ }^{\circ} \mathrm{C}$ but higher than the solidus of the $\mathrm{Al} 6061$ alloy $\left(582{ }^{\circ} \mathrm{C}\right)$, hence melting still occurred. However, unlike the powder heated in nitrogen, little shrinkage was observed after solidification (Figure 1d) and molten $\mathrm{Al}$ alloy leaked out of the bed surface (Figure 1e) due to the poor wettability between the molten $\mathrm{Al}$ and $\mathrm{SiC}[2,3]$ as in the previous studies. Hence, high-quality composites were not produced in this case.

Figure 2 indicates the effect of varying the amount of nitrogen during the production of the same composites by heating the mixtures for $1 \mathrm{~h}$ at a set temperature of $640{ }^{\circ} \mathrm{C}$. The change in temperature inside the powder bed is seen to vary according to the nitrogen flow rate ( 1 to $4 \mathrm{~L} / \mathrm{min}$ ) and, hence, the amount of nitrogen supplied. At nitrogen flow rates of $1-3 \mathrm{~L} / \mathrm{min}$, the temperature increase was first gradual and became rapid at around $645^{\circ} \mathrm{C}$ due to the exothermic nitridation reaction. Furthermore, as the amount of nitrogen increased, the rapid temperature rise occurred sooner, but the maximum temperature was significantly decreased. We reported in the previous study that the temperature at the center of the bed was very high compared to that at the bottom or top during the nitridation of Al powders [25]. This indicates that nitridation begins at the center of the powder bed. Nitrogen gas supplied into the chamber passes through the surface of the powder bed and moves inwards through 
the pore network. Nitrogen reaching the top of the bed is soon discharged through the exhaust pipe. Hence, contact between nitrogen and the Al particle surface is maintained by the continuous supply of fresh nitrogen gas into the chamber. Therefore, nitridation does not occur at the top of the powder bed because the contact time between the nitrogen gas and the Al powder is very short there. By contrast, since the nitrogen gas reaching the center of the bed via the pore network remains in a relatively closed area, nitridation can be initiated during a longer contact time relative to the upper and lower portions of the bed for a given flow rate. Thus, increasing the amount of nitrogen allows a high nitrogen concentration to be maintained in a relatively wider volume in the center of the bed (Figure 2b). Hence, as the quantity of $\mathrm{Al}$ particles experiencing nitridation increases, the heat dissipated by the exotherm increases, and the temperature of $645^{\circ} \mathrm{C}$ is reached sooner, at which stage a rapid temperature rise occurs. This can be seen from the fact that the bed temperature before the onset of rapid temperature rise is relatively higher as the amount of nitrogen increases, as shown in Figure 2a. As will be explained later, however, no rapid temperature rise was observed when the nitrogen flow rate was increased to $4 \mathrm{~L} / \mathrm{min}$.
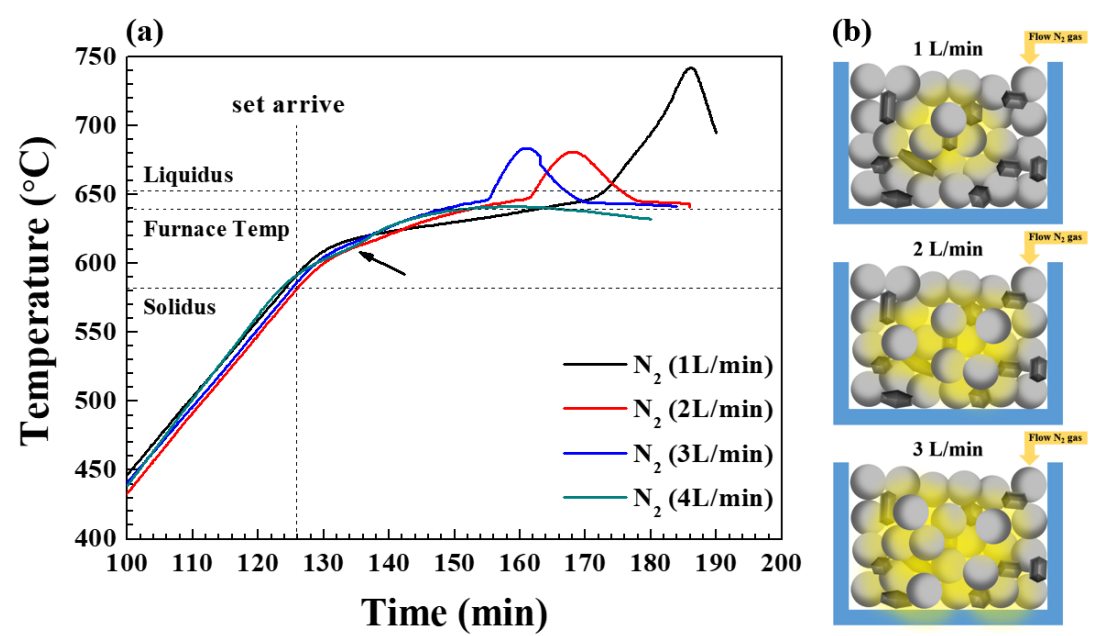

Figure 2. (a) The temperature variation of 20 vol. $\% \mathrm{SiC}(40 \mu \mathrm{m}) / \mathrm{Al} 6061$ composites during heating for 1 $\mathrm{h}$ at a set temperature of $640{ }^{\circ} \mathrm{C}$ under a nitrogen atmosphere at flow rates of $1-4 \mathrm{~L} / \mathrm{min}$. (b) A schematic drawing of the relative concentration of nitrogen in the center of powder bed with increasing flow rates of nitrogen gas.

The degrees of nitridation and the maximum temperatures of the powder bed under various nitrogen flow rates are indicated in Supplementary Figure S1 along with photographic images of the composites in their crucibles and after lathe working. As the inlet flow rate and, hence, the amount of nitrogen supplied increases, the degree of nitridation and maximum temperature both decrease. Since the amount of AlN formed by the nitridation reaction affects the properties of the composite, the amount of AlN should be controlled according to the requirement of the end user.

Figure 3 presents optical micrographs of the composites prepared under different nitrogen flow rates. Uniform distribution of $\mathrm{SiC}$ is observed for all samples and no significant microstructural differences were detected. In addition, the XRD patterns in Figure 4 indicate that AIN was formed in all the composites regardless of nitrogen flow rate and that other reaction products such as $\mathrm{Al}_{4} \mathrm{C}_{3}$ were not detected. In particular, $\mathrm{Al}_{4} \mathrm{C}_{3}$ was not detected at a nitrogen flow rate of $1 \mathrm{~L} / \mathrm{min}$, even though the maximum temperature was approximately that at which this carbide can form $\left(742^{\circ} \mathrm{C}\right)$. As indicated in the above discussion, the temperature rise was localized and the holding time for this temperature range was evidently too short for carbides to form. In this study, composites were prepared at $640^{\circ} \mathrm{C}$, which is below the liquidus $\left(652{ }^{\circ} \mathrm{C}\right)$ of the $\mathrm{Al} 6061$ alloy. Hence, it is possible to produce the composite even at a temperature below the liquidus line, which is one of the advantages of the NISFAC process. Unlike conventional processes involving liquid phases, composites can be produced even 
below the melting point (or liquidus) of $\mathrm{Al}$ and its alloys, which not only reduces the formation of undesirable reactants (e.g. $\mathrm{Al}_{4} \mathrm{C}_{3}$ when $\mathrm{SiC}$ is used), but also reduces the energy-consumption during the manufacturing processes.

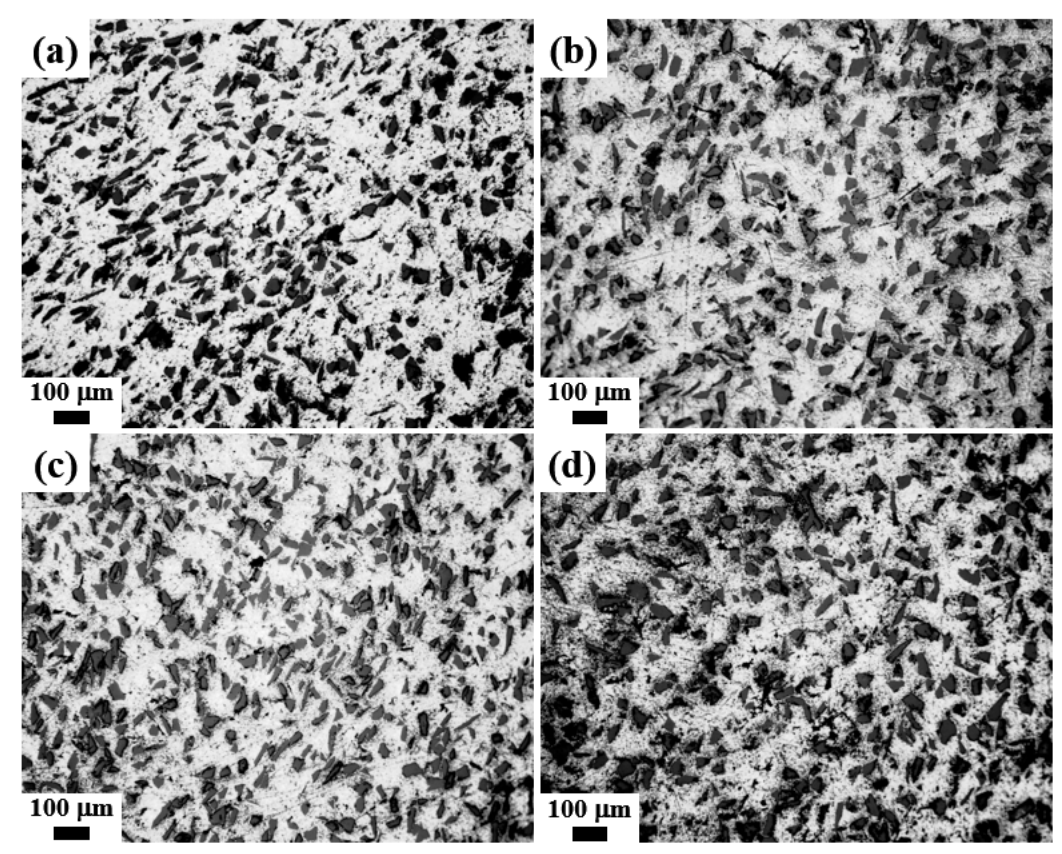

Figure 3. Optical micrographs of $20 \mathrm{vol} \% \mathrm{SiC}(40 \mu \mathrm{m}) / \mathrm{Al} 6061$ composites produced by heating for $1 \mathrm{~h}$ at $640{ }^{\circ} \mathrm{C}$ under various flow rates of nitrogen gas: (a) $1 \mathrm{~L} / \mathrm{min}$, (b) $2 \mathrm{~L} / \mathrm{min}$, (c) $3 \mathrm{~L} / \mathrm{min}$, and (d) $4 \mathrm{~L} / \mathrm{min}$.

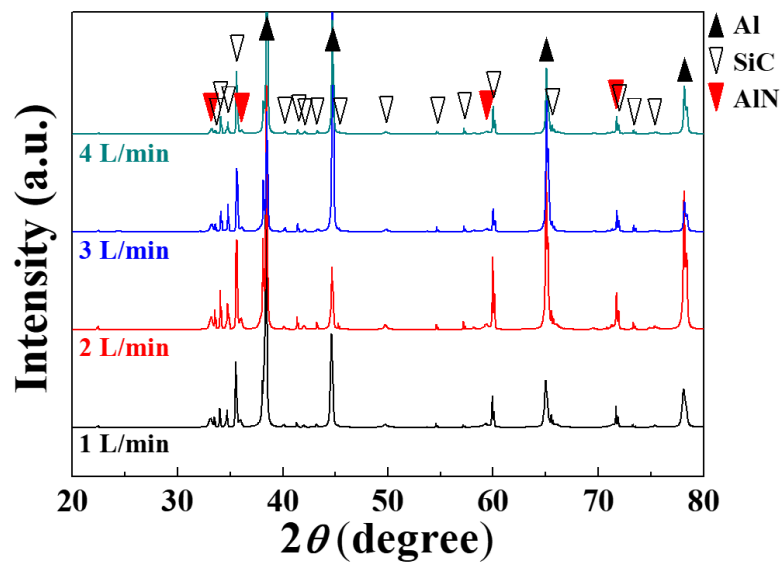

Figure 4. XRD patterns of $20 \mathrm{vol} \% \mathrm{SiC}(40 \mu \mathrm{m}) / \mathrm{Al} 6061$ composites produced by heating for $1 \mathrm{~h}$ at $640{ }^{\circ} \mathrm{C}$ under various flow rates of nitrogen gas.

To examine in detail the effect of nitrogen concentration upon the composite production, the change in the microstructure of the powder bed was tracked during heating under nitrogen flow rates of 1 and $4 \mathrm{~L} / \mathrm{min}$ at a set temperature of $640^{\circ} \mathrm{C}$. The degrees of nitridation and powder bed temperatures of the composites produced with various nitrogen flow rates and heating times are presented in Table 1 , while Supplementary Figure S2 presents photographic images of the respective powders in their crucibles (rows I and V) and in the powder beds (rows II and VI), along with images of the samples after cutting (rows III and VII) and after lathe working (rows IV and VIII). In addition, SEM images of the powder bed microstructures observed at various heating times are presented in Figure 5. It can be seen that a nitrogen flow rate of $1 \mathrm{~L} / \mathrm{min}$ resulted in a very small degree of nitridation $(0.1 \%)$ after heating for 15 mins with a set temperature of $640{ }^{\circ} \mathrm{C}$, so that the sample remained in the powder form. This is because the temperature inside the powder bed remained relatively low $\left(\sim 622{ }^{\circ} \mathrm{C}\right)$ and, 
although this was above the $\mathrm{Al} 6061$ alloy solidus $\left(582^{\circ} \mathrm{C}\right)$, almost no molten $\mathrm{Al}$ was formed (Figure $5 \mathrm{a}$ and Supplementary Figure S2, row II).

Table 1. The degrees of nitridation and temperatures of the powder bed with various nitrogen flow rates and heating times.

\begin{tabular}{|c|c|c|c|c|c|c|c|c|}
\hline \multirow{2}{*}{$\begin{array}{c}\text { Flow Rate of } \mathrm{N}_{2} \text { Gas } \\
(\mathrm{L} / \mathrm{min})\end{array}$} & & \multicolumn{7}{|c|}{ Heating Time (min) } \\
\hline & & 15 & 24 & 32 & 44 & 50 & 56 & 60 \\
\hline \multirow{2}{*}{1} & Bed temperature $\left({ }^{\circ} \mathrm{C}\right)$ & 622 & & 639 & 649 & 654 & 654 & \\
\hline & Degree of nitridation (\%) & 0.1 & & 2.9 & 4.8 & 5.0 & & 8.7 \\
\hline \multirow{2}{*}{4} & Bed temperature $\left({ }^{\circ} \mathrm{C}\right)$ & & 639 & & 639 & & & 641 \\
\hline & Degree of nitridation (\%) & & 2.9 & & 6.3 & & & 8.1 \\
\hline
\end{tabular}

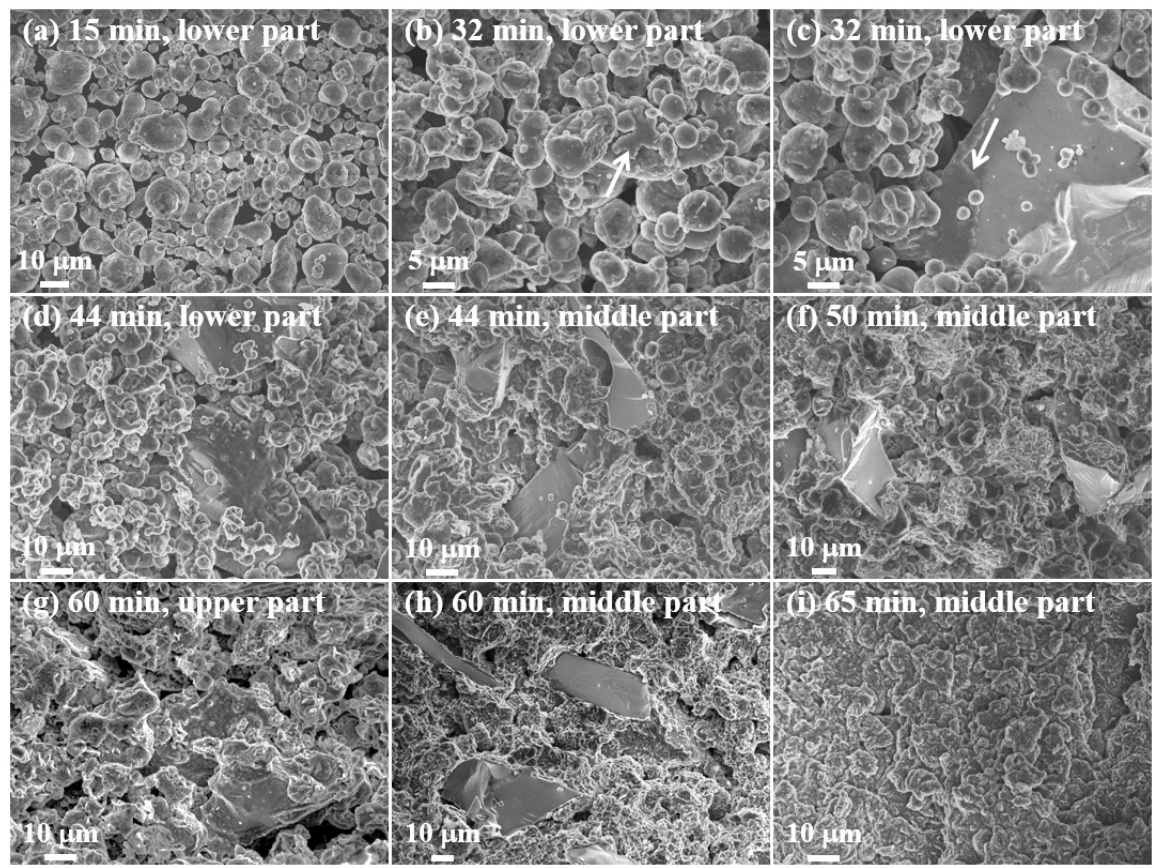

Figure 5. SEM images of the $20 \mathrm{vol} . \% \mathrm{SiC}(40 \mu \mathrm{m}) / \mathrm{Al} 6061$ composites at various positions in the powder bed after various times of heating at a set temperature of $640{ }^{\circ} \mathrm{C}$ under a nitrogen flow rate of 1 L/min: (a-d) lower part, (e,f,h,i) middle part, and (g) upper part.

After 32 minutes of heating, the degree of nitridation increased to $2.9 \%$ and the powder bed temperature increased to $639^{\circ} \mathrm{C}$. However, the amount of molten $\mathrm{Al}$ phase was not enough to form highly dense composites and the final composites were easily broken after solidification (Supplementary Figure S2, row II). In addition, the arrows in Figure 5b,c indicate that molten Al was released from the powder and covered the surfaces of adjacent $\mathrm{Al}$ and $\mathrm{SiC}$ particles. Molten $\mathrm{Al}$ was thus in intimate contact with a very large surface area of the $\mathrm{SiC}$ particles. The melting of the Al powder was caused by the localized increase in temperature above the Al melting temperature due to the exothermic nitridation reaction.

After heating for 44 mins, the top of the powder bed remained in powder form (Figure S2, row I), whereas sufficient shrinkage occurred at the bottom of the powder bed to allow complete solidification (Supplementary Figure S2, row II). This was because the powder bed temperature reached $\sim 649^{\circ} \mathrm{C}$ or more, which is close to the liquidus temperature of the Al 6061 alloy $\left(652{ }^{\circ} \mathrm{C}\right)$, so enough molten $\mathrm{Al}$ was formed to fill the voids in the powder bed (Figure 5e,f). However, as can be seen from the cross-section image in Supplementary Figure S2 (row III) and the SEM image in Figure 5d, some un-melted areas were present near the surface of the powder bed. 
With a nitrogen flow rate of $1 \mathrm{~L} / \mathrm{min}$, the temperature inside the bed continued to rise after 60 mins of heating (Figure 2), hence the nitridation reaction continued. This can also be seen in the cross-section image in Supplementary Figure S2 (row III) and the SEM images in Figure 5g,h. This indicates that much more melt was formed in the center than at the top of the bed. In addition, the amount of molten Al was significantly increased relative to that observed after 50 mins of heating (Figure $5 f, h$ ). As shown in the crucible image, some powder remained on the top even after heating for more than $1 \mathrm{~h}$, but the bed temperature decreased after reaching the maximum temperature of $742{ }^{\circ} \mathrm{C}$ while the amount of molten Al increased (Figure 5i).

The temperature of the bed and the degree of nitridation for the composites after heating for 24 mins under a nitrogen flow rate of $4 \mathrm{~L} / \mathrm{min}$ were $\sim 639^{\circ} \mathrm{C}$ and $2.9 \%$, respectively. These values were similar to those obtained after heating for $32 \mathrm{mins}$ under a flow rate of $1 \mathrm{~L} / \mathrm{min}$. In addition, the crucible images indicate a larger shrinkage after 24 mins of heating at $4 \mathrm{~L} / \mathrm{min}$ than after $32 \mathrm{mins}$ of heating at $1 \mathrm{~L} / \mathrm{min}$, and that the amount of powder remaining on the bed was also reduced and completely solidified at the higher flow rate (Supplementary Figure S2, row V). The images obtained after cutting show similar morphologies after 44 mins of heating at both flow rates. In addition, after 44 mins of heating at $4 \mathrm{~L} / \mathrm{min}$, the peak temperature of $641^{\circ} \mathrm{C}$ has already been passed so that sufficient shrinkage has occurred and the amount of powder remaining on the upper part of the bed has been greatly reduced (Supplementary Figure S2, rows V-VIII).

As shown in Figure 6, these macroscopic changes were also reflected in the microstructure. After heating for 44 mins, the amount of molten $\mathrm{Al}$ obtained at $4 \mathrm{~L} / \mathrm{min}$ was greatly increased relative to that obtained at $1 \mathrm{~L} / \mathrm{min}$. Since the rate of nitridation at a nitrogen flow rate of $4 \mathrm{~L} / \mathrm{min}$ is greater than that at $1 \mathrm{~L} / \mathrm{min}$, the temperature inside the powder bed increases more rapidly and molten $\mathrm{Al}$ is formed relatively faster. As a result, the molten Al fills the pore space inside the bed and blocks the nitrogen supply, suppressing further nitridation and preventing a rapid temperature rise. By contrast, at a nitrogen flow rate of $1 \mathrm{~L} / \mathrm{min}$, the nitridation rate is slow, hence the formation of the liquid phase is slow, nitrogen is supplied into the bed for a relatively longer time, the nitridation time increases and, hence, the temperature rises rapidly due to the increase in the degree of nitridation.

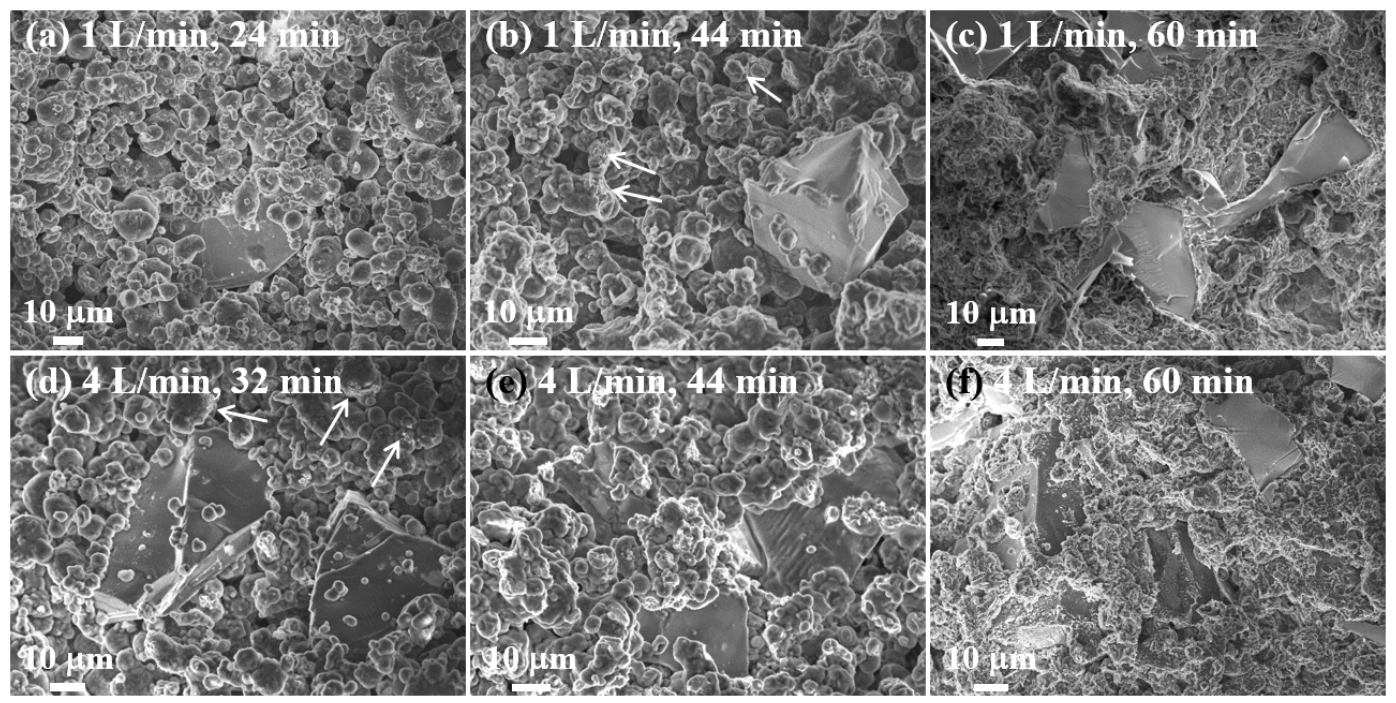

Figure 6. SEM images of 20 vol.\% SiC $(40 \mu \mathrm{m}) / \mathrm{Al} 6061$ composites in the powder bed after heating for various times at a set temperature of $640^{\circ} \mathrm{C}$ under nitrogen flow rates of $1 \mathrm{~L} / \mathrm{min}(\mathbf{a}-\mathbf{c})$ and $4 \mathrm{~L} / \mathrm{min}(\mathbf{d}-\mathbf{f})$.

\subsection{Effect of Heating Temperature at a Fixed Nitrogen Flow Rate}

Since the rapid temperature rise was not observed when heating at a nitrogen flow rate of $4 \mathrm{~L} / \mathrm{min}$, the composite was prepared at a fixed flow rate of $4 \mathrm{~L} / \mathrm{min}$ while heating for $1 \mathrm{~h}$ at set temperatures ranging from 610 to $650{ }^{\circ} \mathrm{C}$ in order to analyze the effect of the production temperature. Figure 7 
shows the temperature changes measured inside the powder bed for various heating temperatures. For all production temperatures, each graph displays several changes of slope such that the second change of slope (marked by the arrows in Figure 7) indicates the temperature rise due to nitridation. The temperature rise stems from two main reasons, namely: i) the exothermic nitridation reaction and ii) the rise in temperature the furnace towards the set temperature. Therefore, the temperature rise due to nitridation may be most clearly distinguished at the lowest set temperature of $610{ }^{\circ} \mathrm{C}$. As shown in Figure 7, at $610^{\circ} \mathrm{C}$, the temperature gradient changes near the solidus temperature $\left(582{ }^{\circ} \mathrm{C}\right)$ of the Al 6061 alloy, indicating that the nitridation of Al begins at very low temperatures. Thus, the time for initiation of nitridation (as indicated by the second change in slope) decreases with increasing production temperature, but the powder bed temperature then increases due to the relatively increased effect of heating. In contrast to the temperature behavior when heating to set temperatures in the range of 610 to $640{ }^{\circ} \mathrm{C}$, heating to $650{ }^{\circ} \mathrm{C}$ generated a sharp internal temperature change at about $645^{\circ} \mathrm{C}$, as was observed in Figure 2. The peak internal temperatures together with the set temperatures are summarized in Supplementary Figure S3 along with photographic images of the composites in the crucibles and after machine working. Thus, the peak internal temperature did not vary significantly with set temperatures except for the set temperature of $650{ }^{\circ} \mathrm{C}$, which exhibited the sharp increase in powder bed temperature. The composites prepared at a set temperature of $610{ }^{\circ} \mathrm{C}$ (Supplementary Figure S3, row II) exhibited a reduced metallic luster and a smaller amount of shrinkage compared to those produced at higher set temperatures. Therefore, in order to manufacture a high-quality composite, manufacturing temperatures of $620^{\circ} \mathrm{C}$ or higher are preferable. In addition, since the maximum temperature inside the powder bed remains below the liquidus of the $\mathrm{Al} 6061$ alloy $\left(652{ }^{\circ} \mathrm{C}\right)$ at set temperatures in the range of 620 to $640{ }^{\circ} \mathrm{C}$, this can greatly limit the formation of undesirable reaction products. When the heating time was increased to $90 \mathrm{mins}$ for the set temperature of $610{ }^{\circ} \mathrm{C}$, however, the crucible shrinkage and metal gloss increased significantly (Supplementary Figure S3, row I). As described above, when manufacturing the composite using the NISFAC process, it is possible to control the amount of molten Al by adjusting the process variables, so that the composite may be manufactured under a variety of conditions. This diversity of processing is another advantage of the NISFAC process. That is, even for the same composite system (e.g., the Al/SiC system studied herein), it is possible to tailor the characteristics of the final product by controlling various process parameters such as the composition of the selected $\mathrm{Al}$ alloy, the matrix powder size, the SiC particle size, the volume fraction of $\mathrm{SiC}$, the manufacturing time and temperature, the nitrogen concentration, etc.

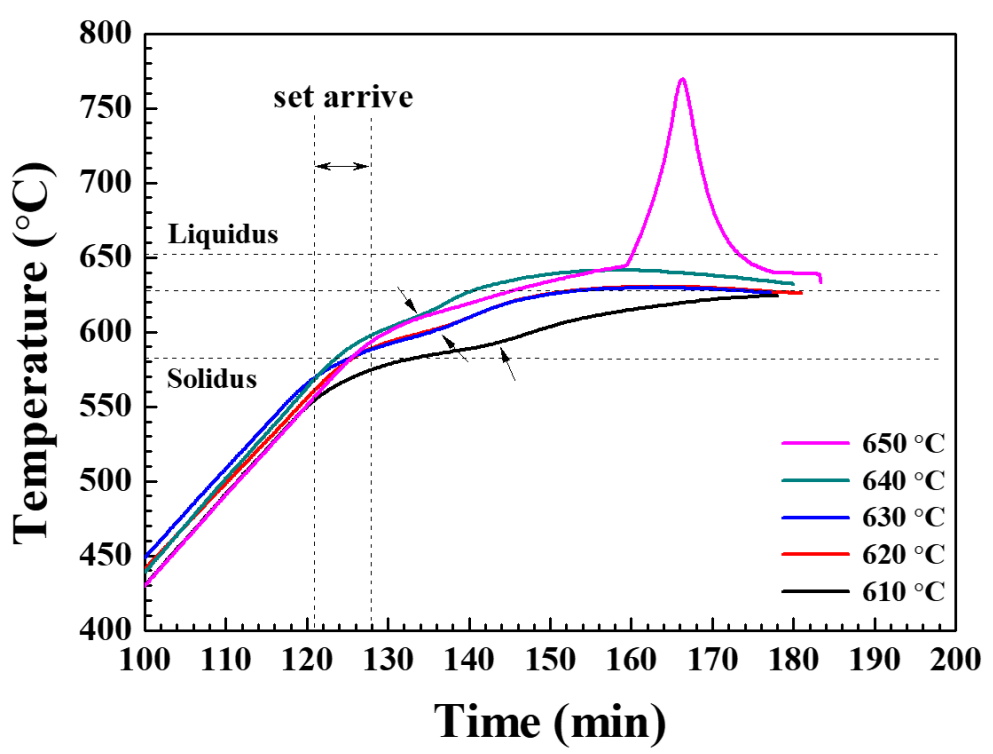

Figure 7. The temperature variation of $20 \mathrm{vol} . \% \mathrm{SiC}(40 \mu \mathrm{m}) / \mathrm{Al} 6061$ composites during heating at various set temperatures $\left(610-650{ }^{\circ} \mathrm{C}\right)$ under a fixed nitrogen flow rate of $4 \mathrm{~L} / \mathrm{min}$. 


\section{Conclusions}

We have reported the effects of process parameters upon the fabrication of $\mathrm{Al} 6061 / \mathrm{SiC}$ composites using the NISFAC process. In this second part of a two-part report, the effects of nitrogen flow rate and heating temperature upon the nitridation behavior of the composites were investigated. When the nitrogen flow rate was too slow, or the set temperature was too low, nitridation did not occur sufficiently to form enough molten $\mathrm{Al}$ to fill the voids in the powder and high-quality composites were not obtained. In summary, the production temperature and time, the size and volume fraction of the SiC particles, and the amount of nitrogen all influence the production of high-quality composites. After years of developing the NISFAC process, we have manufactured composites with various reinforcement materials and various $\mathrm{Al}$ matrices. The greatest advantage of the Al nitridation-based NISFAC process is that it can produce sound composites regardless of the wettability between the $\mathrm{Al}$ matrix and the reinforcement. This means that it is possible to produce countless combinations of composites that have only been theoretically possible so far. Over the years, research has shown that the most important part of the NISFAC process is the formation of sufficient liquid $\mathrm{Al}$ to fill the voids inside the powder bed. In addition, since the amount of liquid $\mathrm{Al}$ is affected by the various process parameters affecting the degree of nitridation, a systematic study of each system is essential. Such research will allow us to freely manufacture composites with properties suitable for the end use (as in the design of alloys) by establishing the optimum process conditions.

Supplementary Materials: The following are available online at http://www.mdpi.com/1996-1944/13/5/1213/s1, Figure S1: The degrees of nitridation, maximum powder bed temperatures, and sample images in the crucibles and after lathe working of the $20 \mathrm{vol} \% \mathrm{SiC}(40 \mu \mathrm{m}) / \mathrm{Al} 6061$ composites produced by heating at $640^{\circ} \mathrm{C}$ for $1 \mathrm{~h}$ under various flow rates of nitrogen gas, Figure S2: Photographic images of the 20 vol.\% SiC $(40 \mu \mathrm{m}) / \mathrm{Al} 6061$ composites produced by heating with a set temperature of $640^{\circ} \mathrm{C}$ for $15-60$ mins under nitrogen flow rates of 1 and $4 \mathrm{~L} / \mathrm{min}$ : in the crucible (rows I and V), the powder bed (rows II and VI), after cutting (rows III and VII), and after lathe working (rows IV and VIII), Figure S3: The maximum temperature, heating time and sample images in the crucible and after lathe working for various fabrication temperatures $\left(610-650^{\circ} \mathrm{C}\right)$.

Author Contributions: K.-B.L. and D.-Y.K. designed and conducted the experiments, D.-Y.K., K.-B.L., H.-J.C., P.-R.C. and H.-S.N. wrote the main manuscript and analyzed the results, D.-Y.K. and K.-B.L. Prepared the samples and Figure 1, Figure 2, Figure 3, Figure 4, Figure 5, Figure 6, Figure 7, Figure S1, Figure S2, and Figure S3. All authors have read and agreed to the published version of the manuscript.

Funding: This research was funded by Basic Science Research Program of the National Research Foundation of Korea (NRF-2017R1A2B4005564) and the Ministry of Trade, Industry and Energy (MOTIE) and Korea Institute for Advancement of Technology (KIAT) through the International Cooperative R\&D program (No. P0006837).

Acknowledgments: This research was supported by the Basic Science Research Program of the National Research Foundation of Korea (NRF-2017R1A2B4005564) and the Ministry of Trade, Industry and Energy (MOTIE) and Korea Institute for Advancement of Technology (KIAT) through the International Cooperative R\&D program (No. P0006837).

Conflicts of Interest: The authors declare no conflict of interest. The funders had no role in the design of the study; in the collection, analyses, or interpretation of data; in the writing of the manuscript, or in the decision to publish the results.

\section{References}

1. Lee, K.B.; Ahn, J.P.; Kim, H.S.; Choi, H.J. Method of Fabricating an Aluminum Matrix Composite and an Aluminum Matrix Composite Fabricated by the Same. U.S. Patent 10,094,006, 9 October 2018.

2. Lee, K.B.; Kim, S.H.; Kim, D.Y.; Cha, P.R.; Kim, H.S.; Choi, H.J.; Ahn, J.P. Aluminum Matrix Composites Manufactured using Nitridation-Induced Self-Forming Process. Sci. Rep. 2019, 9, 20389. [CrossRef] [PubMed]

3. Kim, D.Y.; Cha, P.R.; Nam, H.S.; Choi, H.J.; Lee, K.B. Effect of Material and Process Variables on Characteristics of Nitridation-Induced Self-Formed Aluminum Matrix Composites-Part 1: Effect of Reinforcement Volume Fraction, Size and Processing Temperatures. Unpublished.

4. Rohatgi, P.K.; Gupta, N.; Daoud, A. Synthesis and processing of cast metal-matrix composites and their applications. ASM Handbook 2008, 15, 1149-1164. 
5. Mortensen, A.; Jin, I. Solidification processing of metal matrix composites. Int. Mater. Rev. 1992, 37, 101-128. [CrossRef]

6. Rohatgi, P.; Asthana, R.; Das, S. Solidification, structures, and properties of cast metal-ceramic particle composites. Int. Mat. Rev. 1986, 31, 115-139. [CrossRef]

7. Lloyd, D.J. Particle reinforced aluminium and magnesium matrix composites. Int. Mater. Rev. 1994, 39, 1-23. [CrossRef]

8. Surappa, M.K.; Rohatgi, P.K. Preparation and properties of cast aluminium-ceramic particle composites. J. Mater. Chem. 1981, 16, 983-993. [CrossRef]

9. Lloyd, D.J.; Jin, I. Melt Processed Aluminum Matrix Particle Reinforced Composites. In Comprehensive Composite Materials, 1st ed.; Zweben, C., Kelly, A., Eds.; Elsevier: Amsterdam, The Netherlands, 2000; Volume 3, pp. 555-577.

10. Kaczmar, J.W.; Pietrzak, K.; Włosiński, W. The production and application of metal matrix composite materials. J. Mater. Process. Technol. 2000, 106, 58-67. [CrossRef]

11. Dhanashekar, M.; Kumar, V.S.S. Squeeze Casting of Aluminium Metal Matrix Composites-An Overview. Procedia Eng. 2014, 97, 412-420. [CrossRef]

12. Mortensen, A. Melt Infiltration of Metal Matrix Composites. In Comprehensive Composite Materials, 1st ed.; Zweben, C., Kelly, A., Eds.; Elsevier: Amsterdam, The Netherlands, 2000; Volume 3, pp. 521-554.

13. Aghajanian, M.K.; Burke, J.T.; White, D.R.; Nagelberg, A.S. A new infiltration process for the fabrication of metal matrix composites. SAMPE Q. 1989, 20, 43-46.

14. Sercombe, T.B.; Schaffer, G.B. Rapid manufacturing of aluminum components. Science 2003, 301, $1225-1227$. [CrossRef]

15. Sercombe, T.B.; Schaffer, G.B. On the role of magnesium and nitrogen in the infiltration of aluminium by aluminium for rapid prototyping applications. Acta Mater. 2004, 52, 3019-3025. [CrossRef]

16. Rao, B.S.; Jayaram, V. Pressureless infiltration of Al-Mg based alloys into $\mathrm{Al}_{2} \mathrm{O}_{3}$ preforms: Mechanisms and phenomenology. Acta Mater. 2001, 49, 2373-2385.

17. Meterion. Available online: http://materion.com/products/metal-matrix-composites (accessed on 19 November 2019).

18. DWA Aluminum Composites. Available online: http://www.dwa-usa.com (accessed on 19 November 2019).

19. Hunt, W.H. Processing and Fabrication of Advanced Materials; the Minerals and Metal Materials Society: Warrendale, PA, USA, 1994; pp. 663-683.

20. Lloyd, D.J. Composites Engineering Handbook; Marcel Dekker, Inc.: New York, NY, USA, 1997; pp. 631-670.

21. Gheorghe, I.; Rack, H.J. Powder Processing of Metal Matrix Composites. In Comprehensive Composite Materials, 1st ed.; Zweben, C., Kelly, A., Eds.; Elsevier: Amsterdam, The Netherlands, 2000; Volume 3, pp. 679-700.

22. Breval, E.; Aghajanian, M.K.; Biel, J.P.; Antolin, S. Structure of Aluminum Nitride/Aluminum and Aluminum Oxide/Aluminum Composites Produced by the Directed Oxidation of Aluminum. J. Am. Ceram. Soc. 1993, 76, 1865-1868. [CrossRef]

23. Zulfia, A.; Hand, R.J. The production of Al-Mg alloy/SiC metal matrix composites by pressureless infiltration. J. Mater. Sci. 2002, 37, 955-961. [CrossRef]

24. Florea, R.M.; Bălţătescu, O.; Buzăianu, A.; Carcea, I. Investigation Techniques of In Situ AlMg/AlN Metal Matrix Composites via Reactive Gas Injection. Adv. Mater. Res. 2013, 837, 283-289. [CrossRef]

25. Kim, S.H.; Noh, J.H.; Ahn, J.P.; Lee, J.C.; Kwon, H.; Lee, J.; Lee, K.B. Effects of surface oxide on the nitridation behavior of aluminum particles. Metall. Mater. Trans. A 2015, 46, 496. [CrossRef]

(C) 2020 by the authors. Licensee MDPI, Basel, Switzerland. This article is an open access article distributed under the terms and conditions of the Creative Commons Attribution (CC BY) license (http://creativecommons.org/licenses/by/4.0/). 